\title{
Explaining Time Changes in Oral Health-Related Quality of Life in England: a decomposition analysis
}

Total Word Count: 2,959

${ }^{1}$ Department of Epidemiology and Public Health University College London, London, United Kingdom

2 Departamento de Salud Colectiva, Facultad de Odontología Universidad Nacional de Colombia, Bogotá, Colombia

${ }^{3}$ School of Dental Sciences and Centre for Oral Health Research Newcastle University, Newcastle Upon Tyne, United Kingdom

${ }^{4}$ Economics, Newcastle Business School

Newcastle University, Newcastle Upon Tyne, United Kingdom

${ }^{5}$ NUS Faculty of Dentistry and University Dental Cluster, NUH National University of Singapore, Singapore, Singapore

Corresponding author:

Carol C. Guarnizo-Herreño 1-19 Torrington Place | London WC1E 7HB

Tel: +44 (0)20 76791699 | Fax: +44 (0)20 78130280

Email: c.guarnizo-herreno.11@ucl.ac.uk 


\section{Abstract}

2 Background: Oral diseases are highly prevalent and impact upon oral health-related quality of 3 life (OHRQoL). However, time changes in OHRQoL have been scarcely investigated in the current context of general improvement in clinical oral health. This study aims to examine changes in OHRQoL between 1998 and 2009 amongst adults in England, and to analyse the contribution of demographics, socioeconomic characteristics and clinical oral health measures.

Methods: Using data from two nationally representative surveys in England, we assessed changes in the Oral Health Impact Profile-14 (OHIP-14), in both the sample overall $(n=12,027)$ and by quasi-cohorts. We calculated the prevalence and extent of oral impacts and summary OHIP-14 scores. An Oaxaca-Blinder type decomposition analysis was used to assess the contribution of demographics (age, gender, marital status), socioeconomic position (education, occupation) and clinical measures (presence of decay, number of missing teeth, having advanced periodontitis).

Results: There were significant improvements in OHRQoL, predominantly among those that experienced oral impacts occasionally, but no difference in the proportion with frequent oral impacts. The decomposition model showed that $43 \%(-4.07 /-9.47)$ of the decrease in prevalence of oral impacts reported occasionally or more often was accounted by the model explanatory variables. Improvements in clinical oral health and the effect of aging itself accounted for most of the explained change in OHRQoL, but the effect of these factors varied substantially across the lifecourse and quasi-cohorts.

21 Conclusions: These decomposition findings indicate that broader determinants could be primarily targeted to influence OHRQoL in different age groups or across different adult cohorts. 


\section{INTRODUCTION}

2

3 Over the past fifty years, there has been a major shift in health status. Improved life expectancy

has been largely associated with better living standards and improved therapies for many lifethreatening conditions.[1] In economically prosperous countries, the financial burden of healthcare has shifted towards the management of chronic conditions and comorbidities, often with rapidly increasing costs. Concepts of measurement have also broadened, from purely clinical assessment of disease to the inclusion of the people's perceptions, such as quality of life and well-being, so managing symptom severity rather than complete cure is often a more appropriate primary goal.

In the context of oral health, the most prevalent diseases are dental caries and periodontal disease.[2] These are abundant chronic diseases and their manifestations accumulate and change over time, with the potential of tooth loss as an endpoint. Oral diseases result in considerable burden on people's quality of life[3] and high costs,[4] so it is important to have an understanding of their impact on the population and how this changes across life.

Describing the impact of oral conditions is complex. The way a person interprets and feels about any oral condition will vary with their age but also between generations. A further consideration is whether health gains over time are shared evenly across the population. Indeed, there is a body of evidence suggesting that there are growing socio-economic inequalities in health.[5-9] Predicting how the impact of oral health may change over the next ten or twenty years is important as any organisation needs to understand, plan and manage problems, with sensible decisions taken about a likely future. Such predictions must be based on up-to-date evidence identifying how oral diseases and their impact on people's quality of life are changing, whether this is happening in different ways across the population, and why such changes are occurring.

Time changes in oral impacts among adult populations have been previously investigated in cohort studies with follow-up periods of up to seven years.[10-13] Data from national population surveys have been helpful at given points in time, but they are cross-sectional and have provided only limited evidence about changes over time.[14] In the United Kingdom, national oral health surveys have been undertaken every 10 years since 1968. The most recent were in 1998 and 2009, and both included clinical and subjective measures of oral health, including oral health 
1 related quality of life (OHRQoL). This allows the opportunity for time point comparisons between different generations, but also within generations as people age, thereby looking at, and potentially explaining, both generation and age effects.

4

This study examined changes in OHRQoL amongst nationally representative samples of adults in England across an eleven-year time period, with subsequent deconstruction of the relative contribution of demographic, socioeconomic and clinical oral health characteristics to the observed changes for different age groups.

\section{METHODS}

12

\section{Data Source}

14 We analysed data from the 1998 and 2009 Adult Dental Health Surveys (ADHS), the two most recent national surveys of adults' oral health in the UK.[15, 16] Both employed a multi-stage cluster and probabilistic sampling design that provided representative data of individuals aged 16 years and over. Households were selected initially, then all adults in selected households were invited to participate in an interview and those with natural teeth were also invited to a clinical dental examination. Full details of the surveys' designs can be found elsewhere.[15, 16$]$

\section{Study measures}

Interviews in both surveys included the Oral Health Impact Profile-14 (OHIP-14), a widely used 14-item OHRQoL measure.[17, 18] Individuals were asked how often they had experienced negative impacts due to oral problems during the last 12 months with responses of never, hardly ever, occasionally, fairly often and very often. We derived four summary measures:[19-23] a) a binary variable for responding 'very often' or 'fairly often' to any question (FOVO prevalence); b) a binary variable for those that responded 'occasionally', 'fairly often' or 'very often' to any question (OFOVO prevalence); c) the number of items with responses of 'occasionally', 'fairly often' or 'very often' (OFOVO extent); d) the OHIP-14 score, corresponding to the sum of ordinal responses, with higher scores indicating poorer OHRQoL.

Demographic characteristics included age, gender and marital status. Socioeconomic characteristics included educational attainment (no qualifications; qualifications below degree 
1 level; qualifications at degree level or equivalent) and occupational social class (managerial and professional; intermediate; routine and manual, according to the UK three-category National Statistics Socio-Economic Classification (NS-SEC)). We used three measures representing different aspects of clinical oral health: presence of decay or any unsound teeth, number of missing teeth, and having advanced periodontitis (presence of probing pocket depth $\geq 6 \mathrm{~mm}$ ). These clinical measures were identified as the main oral health issues worldwide.[2] They also exhibited significant differences between 1998 and 2009 in our data, therefore could potentially explain changes in OHRQoL.

\section{Statistical analysis}

Firstly, changes between 1998 and 2009 for each OHIP-14 summary measure were evaluated in the whole sample and also by age groups. In addition, we looked at changes by quasi-cohorts, aiming to capture cohort effects by defining groups as they aged during this eleven-year period, e.g. participants aged 16-34 years in 1998 were compared to those aged 27-45 years in 2009.

We then used decomposition analyses to evaluate the contribution of demographic, socioeconomic and clinical oral health characteristics to changes in OHRQoL (measured by OFOVO prevalence, as it was the most meaningful outcome that showed significant change) between 1998 and 2009, in both the whole sample and by quasi-cohorts. Oaxaca-Blinder type decomposition models are used to quantify how much of the difference in an outcome between two groups (or time periods) is explained by respective differences in the distributions of selected independent variables.[24, 25] Such models have previously been used to understand health inequalities and time trends in health and health care outcomes.[26-29] We quantified how much of the decrease in OFOVO prevalence between 1998 and 2009 was explained by changes in socio-demographic (age, gender, marital status, education, occupational social class) and clinical variables (presence of decay or unsound teeth, number of missing teeth, having advanced periodontitis) over this period. Since the dependent variable was binary, we used the Fairlie model for nonlinear binary outcomes (a nonlinear variant of Oaxaca-Blinder decomposition).[24] The independent variables were categorical, apart from age and number of missing teeth, which were continuous. 
1 Various steps were followed to decompose the difference in OFOVO prevalence between the two surveys. First, conditional probabilities of the outcome were predicted for each observation. Then, to equal the size of the 1998 sample, a subsample of individuals in 2009 (the largest sample) was randomly selected. In these two equally-sized samples, each individual/observation was rank-ordered according to the predicted outcome probability and observations with equal rank in the two samples were matched. Next, for each independent variable, values of the variable in 1998 were replaced by values of this variable from the matched 2009 observations. The difference in the outcome probability when using the 1998 and 2009 values was then estimated to represent the time difference explained by a particular independent variable. Since results depend on the specific selected 2009 subsample, we obtained 2000 randomly selected ADHS 2009 subsamples and the decomposition results were averaged across these subsamples. Additionally, as the order in which values are substituted (from 1998 to 2009) could affect the decomposition results for each variable category, we randomly selected the category order for each ADHS 2009 subsample, expecting that the 2000 replications approximate the average result from all potential variable-category orderings.[24, 25] For sensitivity analysis, we additionally carried out similar decomposition analyses for the mean OHIP-14 score change.

Analyses referred to data from 12,027 dentate participants in England ( $n=3,010$ in 1998 and $n=9,017$ in 2009) as OHIP-14 questions were only asked to the dentate adults in ADHS 1998. For decomposition analyses, the sample was further restricted to participants that were clinically examined and those aged $\geq 21$ to ensure accurate data on educational attainment. Furthermore, 204 individuals were excluded from ADHS 1998 and 587 from ADHS 2009 because of incomplete information on socio-demographic or clinical variables. Hence, the decomposition analyses sample contained 6,549 individuals ( $n=1,842$ in 1998; $n=4,707$ in 2009). No imputation of missing data was carried out as missing data was less than 7\% for all study variables.[30] Analyses used the surveys' sampling probability weights, accounting for the sampling strategy and nonresponse, to provide population representative data.

\section{RESULTS}

30 In the overall sample, there were significant reductions in the summary OHIP measures between 1998 and 2009, except from FOVO prevalence which showed no significant change. When 
1 years but a reduction by almost half in the oldest group ( $75+$ years). OFOVO prevalence, OFOVO

2 extent, and the mean OHIP-14, showed significant reductions across all age groups apart from

3 55-74 years-olds (Table 1). Examination of time changes for each OHIP-14 item showed larger

4 declines in prevalence in the 'occasionally' and 'hardly ever', rather than the 'fairly often' or 'very

5 often' ratings (Appendix Table 1).

6

7 Assessing time changes for the different quasi-cohorts (Table 2), we found that FOVO prevalence

8 remained very similar between 1998 and 2009 across quasi-cohorts, whereas OFOVO prevalence

9 decreased by around 10 percentage points over that period. The decline was slightly larger in

10 the youngest cohort (13.3\%) and became smaller in older cohorts (7.6\% in oldest). Reductions

11 in OFOVO extent and the mean OHIP score were similar across cohorts with declines of around

120.3 and 1.5 respectively.

13

14

15

16

17

18

19

20

21

22 
Table 1 - Changes in summary OHIP-14 measures: dentate adults in England, 1998 and 2009, by age groups (weighted estimates)

\begin{tabular}{|c|c|c|c|c|c|c|c|c|c|c|c|c|}
\hline \multirow{2}{*}{ Age } & \multicolumn{3}{|c|}{ FOVO (\%) } & \multicolumn{3}{|c|}{ OFOVO (\%) } & \multicolumn{3}{|c|}{ Mean extent OFOVO (SD) } & \multicolumn{3}{|c|}{ Mean OHIP-14 score (SD) } \\
\hline & 1998 & 2009 & $p$-value ${ }^{a}$ & 1998 & 2009 & $p$-value ${ }^{a}$ & 1998 & 2009 & $p$-value ${ }^{a}$ & 1998 & 2009 & $p$-value ${ }^{a}$ \\
\hline $\begin{array}{l}\text { All } \\
(16+)\end{array}$ & 15.6 & 15.2 & 0.607 & 50.8 & 39.2 & $<0.001$ & $1.6(2.4)$ & $1.2(2.2)$ & $<0.001$ & $5.1(6.6)$ & $3.5(6.3)$ & $<0.001$ \\
\hline $16-34$ & 16.1 & 14.0 & 0.119 & 52.1 & 36.1 & $<0.001$ & $1.6(1.7)$ & $1.1(1.8)$ & $<0.001$ & $5.4(4.7)$ & $3.3(5.0)$ & $<0.001$ \\
\hline $35-54$ & 15.8 & 16.2 & 0.802 & 53.0 & 41.0 & $<0.001$ & $1.7(2.0)$ & $1.3(2.3)$ & $<0.001$ & $5.3(5.3)$ & $3.8(6.3)$ & $<0.001$ \\
\hline $55-74$ & 12.5 & 16.2 & 0.021 & 44.2 & 41.5 & 0.222 & $1.3(1.7)$ & $1.2(2.3)$ & 0.550 & $4.2(5.2)$ & $3.5(6.6)$ & 0.016 \\
\hline $75+$ & 24.2 & 12.8 & 0.002 & 50.2 & 35.7 & 0.004 & $1.3(1.7)$ & $0.8(1.6)$ & 0.025 & $4.2(4.8)$ & $2.5(4.8)$ & 0.006 \\
\hline
\end{tabular}

a $p$-values from tests for differences between 1998 and 2009

FOVO: prevalence of responding 'very often' or 'fairly often' to any OHIP-14 question

OFOVO: prevalence of responding 'occasionally', 'fairly often' or 'very often' to any OHIP-14 question 
1 Table 2 - Changes in OHIP-14 summary measures, demographics, socioeconomics and clinical oral health by quasi-

2 cohorts: dentate adults in England, 1998 \& 2009 (weighted estimates)

\begin{tabular}{|c|c|c|c|c|c|c|c|c|c|}
\hline & \multicolumn{3}{|c|}{ Quasi-Cohort 1} & \multicolumn{3}{|c|}{ Quasi-Cohort 2} & \multicolumn{3}{|c|}{ Quasi-Cohort 3} \\
\hline & $\begin{array}{c}1998 \\
(21-34)\end{array}$ & $\begin{array}{c}2009 \\
(32-45)\end{array}$ & $p$-value ${ }^{a}$ & $\begin{array}{c}1998 \\
(35-54)\end{array}$ & $\begin{array}{c}2009 \\
(46-65)\end{array}$ & $p$-value ${ }^{a}$ & $\begin{array}{c}1998 \\
(55-74)\end{array}$ & $\begin{array}{c}2009 \\
(66-85)\end{array}$ & $p$-value ${ }^{a}$ \\
\hline \multicolumn{10}{|l|}{$\begin{array}{l}\text { OHIP-14 summary } \\
\text { measures }\end{array}$} \\
\hline FOVO (\%) & 16.7 & 15.6 & 0.464 & 15.8 & 17.1 & 0.341 & 12.5 & 13.4 & 0.570 \\
\hline OFOVO (\%) & 53.2 & 39.9 & $<0.001$ & 53.0 & 42.2 & $<0.001$ & 44.2 & 36.6 & 0.001 \\
\hline $\begin{array}{l}\text { Mean extent } \\
\text { OFOVO (SD) }\end{array}$ & $1.7(1.9)$ & $1.3(2.2)$ & $<0.001$ & $1.7(2.0)$ & $1.4(2.4)$ & $<0.001$ & $1.3(1.7)$ & $0.9(1.8)$ & $<0.001$ \\
\hline $\begin{array}{l}\text { Mean OHIP } \\
\text { score (SD) }\end{array}$ & $5.5(5.1)$ & $3.7(6.2)$ & $<0.001$ & $5.3(5.4)$ & $3.8(6.8)$ & $<0.001$ & $4.2(5.1)$ & $2.7(5.4)$ & $<0.001$ \\
\hline \multicolumn{10}{|l|}{ Demographics } \\
\hline Mean age (SD) & $28.5(3.1)$ & $38.8(3.7)$ & $<0.001$ & $43.8(4.6)$ & $54.9(6.1)$ & $<0.001$ & $63.1(4.3)$ & $73.5(6.3)$ & $<0.001$ \\
\hline \multicolumn{10}{|l|}{ Gender (\%) } \\
\hline Female & 49.6 & 49.8 & 0.922 & 48.0 & 46.9 & 0.641 & 48.7 & 49.0 & 0.925 \\
\hline Male & 50.4 & 50.2 & 0.922 & 52.0 & 53.1 & 0.641 & 51.3 & 51.0 & 0.925 \\
\hline \multicolumn{10}{|l|}{ Marital status (\%) } \\
\hline Married/cohabiting & 41.7 & 63.6 & $<0.001$ & 70.0 & 65.5 & 0.038 & 76.2 & 56.5 & $<0.001$ \\
\hline Single & 52.1 & 24.2 & $<0.001$ & 14.0 & 10.6 & 0.032 & 4.6 & 7.6 & 0.060 \\
\hline Separated/divorced & 6.1 & 11.5 & $<0.001$ & 5.0 & 19.7 & 0.006 & 7.2 & 10.6 & 0.079 \\
\hline Widowed & 0.1 & 0.7 & 0.036 & 1.0 & 4.2 & $<0.001$ & 12.0 & 25.3 & $<0.001$ \\
\hline \multicolumn{10}{|l|}{ Socioeconomics } \\
\hline \multicolumn{10}{|l|}{$\begin{array}{l}\text { Educational } \\
\text { attainment (\%) }\end{array}$} \\
\hline Degree/equivalent & 21.8 & 37.4 & $<0.001$ & 20.6 & 26.6 & 0.002 & 10.5 & 19.2 & $<0.001$ \\
\hline Below degree level & 69.8 & 55.1 & $<0.001$ & 63.2 & 59.8 & 0.129 & 49.0 & 46.2 & 0.403 \\
\hline No qualifications & 8.4 & 7.5 & 0.572 & 16.2 & 13.6 & 0.112 & 40.5 & 34.6 & 0.076 \\
\hline \multicolumn{10}{|l|}{$\begin{array}{l}\text { Occupation } \\
\text { (NS-SEC) (\%) }\end{array}$} \\
\hline $\begin{array}{l}\text { Managerial and } \\
\text { professional }\end{array}$ & 35.6 & 53.3 & $<0.001$ & 43.2 & 45.1 & 0.412 & 33.2 & 42.5 & 0.004 \\
\hline Intermediate & 23.1 & 18.8 & 0.054 & 19.0 & 20.7 & 0.337 & 23.8 & 23.0 & 0.782 \\
\hline $\begin{array}{l}\text { Routine and } \\
\text { manual }\end{array}$ & 41.3 & 27.9 & $<0.001$ & 37.8 & 34.2 & 0.102 & 43.0 & 34.4 & 0.009 \\
\hline \multicolumn{10}{|l|}{ Clinical oral health } \\
\hline $\begin{array}{l}\text { Decay or any } \\
\text { unsound teeth (\%) }\end{array}$ & 60.0 & 37.8 & $<0.001$ & 51.4 & 42.1 & $<0.001$ & 52.6 & 41.5 & $<0.001$ \\
\hline $\begin{array}{l}\text { Mean number of } \\
\text { missing teeth (SD) }\end{array}$ & $3.7(1.9)$ & $4.1(2.8)$ & 0.001 & $6.1(3.4)$ & $7.4(5.3)$ & $<0.001$ & $12.6(5.8)$ & $12.9(7.8)$ & 0.583 \\
\hline $\begin{array}{l}\text { Any pockets } \geq 6 \mathrm{~mm} \\
(\%)\end{array}$ & 2.4 & 6.8 & $<0.001$ & 5.9 & 14.1 & $<0.001$ & 11.7 & 14.6 & 0.207 \\
\hline
\end{tabular}

a $p$-values from tests for differences between 1998 and 2009

FOVO: prevalence of responding 'very often' or 'fairly often' to any OHIP-14 question

OFOVO: prevalence of responding 'occasionally', 'fairly often' or 'very often' to any OHIP-14 question 
1 The decomposition of the 1998-2009 change in OFOVO prevalence for the sample overall (Table

2 3) showed that $43 \%(-4.07 /-9.47)$ of the decrease in OFOVO was explained by changes in the

3 distribution of socio-demographic characteristics and clinical oral health indicators. The decline

4 in the prevalence of decay or unsound teeth (Appendix Table 2) and the increase in mean age each explained $16.2 \%$, while the decrease in number of missing teeth accounted for $11.0 \%$ of the reduction in OFOVO (Table 3). In contrast, the increase in prevalence of pocketing $\geq 6 \mathrm{~mm}$ worked against the overall decrease in OFOVO (-2.7\%). Other demographic and socioeconomic variables had no significant effect on the change in OFOVO over time (Table 3). When clinical variables were removed from the model, the proportion of the 1998-2009 change in OFOVO explained greatly decreased: from $43 \%$ in the full model (Table 3 ) to $12 \%$ in the model without clinical variables (Appendix Table 3). Decomposing the mean OHIP-14 score change, results confirmed that age and clinical characteristics were the most important factors. In this model, changes in the distribution of the socio-demographic and clinical variables explained $53 \%$ of the decrease in OHIP-14 score (Appendix Table 4).

Finally, time differences in OFOVO prevalence were decomposed for each quasi-cohort, assessing changes as generations aged (Table 4). For the two younger quasi-cohorts, the decomposition model explained around $30 \%$ of the decrease in OFOVO prevalence but for the oldest quasi-cohort the model accounted for $85 \%$ of the decrease in OFOVO. In the youngest quasi-cohort, the reduction in decayed or unsound teeth accounted for $22 \%$, whilst an improvement in social class accounted for $13 \%$ of the decline in OFOVO (Table 4). Increasing age and a reduction in decay and unsound teeth accounted for $50 \%$ and $12 \%$ respectively of the decrease in OFOVO in the middle quasi-cohort and for $92 \%$ and $11 \%$ respectively of the decrease in OFOVO in the oldest quasi-cohort. Increases in the number of missing teeth and the prevalence of periodontal pocketing $\geq 6 \mathrm{~mm}$ in these quasi-cohorts as they aged worked against the observed declines in OFOVO between 1998 and 2009 (Table 4). 
Table 3 - Non-linear decomposition of the change in the OHIP-14 prevalence (OFOVO), in dentate adults aged $\geq 21$ in England, between 1998 \& 2009.

\begin{tabular}{|c|c|c|c|}
\hline Predicted prevalence OFOVO 1998 & \multicolumn{2}{|c|}{0.5204} & \\
\hline Predicted prevalence OFOVO 2009 & \multicolumn{2}{|c|}{0.4257} & \\
\hline Difference in prevalence between 1998/2009 & \multicolumn{2}{|c|}{-0.0947} & \\
\hline Difference explained by decomposition model & \multicolumn{2}{|c|}{-0.0407} & \\
\hline Explained ${ }^{\text {a }} \%$ & \multicolumn{2}{|c|}{43.02} & \\
\hline Unexplained ${ }^{\text {a } \%}$ & \multicolumn{2}{|c|}{56.98} & \\
\hline \multicolumn{4}{|c|}{$\begin{array}{l}\text { Contributions of study variables (explained component)-Coefficient (SE), } p \text {-value and \% contribution } \\
\text { (where } p<0.05 \text { ) }\end{array}$} \\
\hline \multicolumn{4}{|c|}{ Demographics } \\
\hline Age & $-0.0153(0.0019)$ & $<0.001$ & $16.2 \%$ \\
\hline Gender (female) & $0.0002(0.0002)$ & 0.269 & \\
\hline Marital status & $0.0014(0.0009)$ & 0.108 & \\
\hline \multicolumn{4}{|l|}{ Socioeconomics } \\
\hline Educational attainment & $-0.0027(0.0023)$ & 0.245 & \\
\hline Occupational social class (NS-SEC) & $-0.0014(0.0013)$ & 0.297 & \\
\hline \multicolumn{4}{|l|}{ Clinical oral health } \\
\hline Existence of decay or any unsound teeth & $-0.0153(0.0021)$ & $<0.001$ & $16.2 \%$ \\
\hline Number of missing teeth & $-0.0104(0.0010)$ & $<0.001$ & $11.0 \%$ \\
\hline Any pockets $\geq 6 \mathrm{~mm}$ & $0.0026(0.0007)$ & $<0.001$ & $(-) 2.7 \%$ \\
\hline
\end{tabular}

a Proportion of the 1998/2009 change in OFOVO explained and unexplained by the decomposition model.

Explained= related to change in endowments, attributable to 1998-2009 changes in the magnitude of the explanatory variables. Unexplained= related to change in coefficients, attributable to 1998-2009 changes in the effects of the explanatory variables.

OFOVO: prevalence of responding 'occasionally', 'fairly often' or 'very often' to any OHIP-14 question 
1 Table 4 - Non-linear decomposition of the change in the OHIP-14 prevalence (OFOVO), by quasi-cohort of dentate

2 adults in England, between 1998 \& 2009

\begin{tabular}{|c|c|c|c|}
\hline & Quasi-Cohort 1 & Quasi-Cohort 2 & $\begin{array}{c}\text { Quasi-Cohort } 3 \\
\text { 1998 (55-74 vears) }\end{array}$ \\
\hline & 1998 (21-34 years) & 1998 (35-54 years) & 1998 (55-74 years) \\
\hline & 2009 (32-45 years) & 2009 (46-65 years) & 2009 (66-85 years) \\
\hline & $n=1,872$ & $n=2,632$ & $n=1,300$ \\
\hline $\begin{array}{l}\text { Predicted prevalence } \\
\text { OFOVO } 1998\end{array}$ & 0.5515 & 0.5340 & 0.4520 \\
\hline $\begin{array}{l}\text { Predicted prevalence } \\
\text { OFOVO } 2009\end{array}$ & 0.4403 & 0.4399 & 0.3754 \\
\hline $\begin{array}{l}\text { Difference in prevalence } \\
\text { between } 1998 \text { \& } 2009\end{array}$ & -0.1112 & -0.0941 & -0.0767 \\
\hline $\begin{array}{l}\text { Difference explained by } \\
\text { the decomposition model }\end{array}$ & -0.0354 & -0.0273 & -0.0655 \\
\hline Explained a \% & 31.80 & 29.00 & 85.36 \\
\hline Unexplained a \% & 68.20 & 71.00 & 14.64 \\
\hline
\end{tabular}

Contributions of study variables (explained component) - Coefficient (SE), $p$-value and \% contribution (where $p<0.05$ )

Demographics

\begin{tabular}{|c|c|c|c|c|c|c|c|c|c|}
\hline Age & $\begin{array}{r}-0.0025 \\
(0.0332)\end{array}$ & 0.939 & & $\begin{array}{r}-0.0468 \\
(0.0207)\end{array}$ & 0.024 & $49.7 \%$ & $\begin{array}{r}-0.0704 \\
(0.0295)\end{array}$ & 0.017 & $91.8 \%$ \\
\hline Gender (female) & $\begin{array}{r}0.0001 \\
(0.0007)\end{array}$ & 0.883 & & $\begin{array}{r}-0.0003 \\
(0.0004)\end{array}$ & 0.476 & & $\begin{array}{r}0.0011 \\
(0.0013)\end{array}$ & 0.403 & \\
\hline Marital status & $\begin{array}{r}-0.0090 \\
(0.0079)\end{array}$ & 0.251 & & $\begin{array}{r}0.0013 \\
(0.0025)\end{array}$ & 0.630 & & $\begin{array}{r}0.0038 \\
(0.0063)\end{array}$ & 0.534 & \\
\hline \multicolumn{10}{|l|}{ Socioeconomics } \\
\hline Educational attainment & $\begin{array}{r}-0.0036 \\
(0.0043)\end{array}$ & 0.404 & & $\begin{array}{r}-0.0010 \\
(0.0019)\end{array}$ & 0.601 & & $\begin{array}{r}0.0042 \\
(0.0040)\end{array}$ & 0.294 & \\
\hline Occupation (NS-SEC) & $\begin{array}{r}-0.0143 \\
(0.0049)\end{array}$ & 0.003 & $12.9 \%$ & $\begin{array}{r}0.0019 \\
(0.0011)\end{array}$ & 0.067 & & $\begin{array}{c}-0.0024 \\
(0.0032)\end{array}$ & 0.461 & \\
\hline \multicolumn{10}{|l|}{ Clinical oral health } \\
\hline Decay or unsound teeth & $\begin{array}{r}-0.0240 \\
(0.0058)\end{array}$ & $<0.001$ & $21.6 \%$ & $\begin{array}{r}-0.0113 \\
(0.0025)\end{array}$ & $<0.001$ & $12.0 \%$ & $\begin{array}{r}-0.0081 \\
(0.0035)\end{array}$ & 0.021 & $10.6 \%$ \\
\hline Number of missing teeth & $\begin{array}{r}0.0123 \\
(0.0024)\end{array}$ & $<0.001$ & $(-) 11.1 \%$ & $\begin{array}{r}0.0225 \\
(0.0027)\end{array}$ & $<0.001$ & $(-) 23.9 \%$ & $\begin{array}{r}0.0058 \\
(0.0014)\end{array}$ & $<0.001$ & $(-) 7.6 \%$ \\
\hline Any pockets $\geq 6 \mathrm{~mm}$ & $\begin{array}{r}0.0058 \\
(0.0026)\end{array}$ & 0.025 & $(-) 5.2 \%$ & $\begin{array}{r}0.0063 \\
(0.0026)\end{array}$ & 0.015 & $(-) 6.7 \%$ & $\begin{array}{r}0.0003 \\
(0.0015)\end{array}$ & 0.842 & \\
\hline
\end{tabular}

3 a Proportion of the 1998/2009 change in OFOVO explained and unexplained by the decomposition model

4 OFOVO: prevalence of responding 'occasionally', 'fairly often' or 'very often' to any OHIP-14 question 
Clinical oral health has radically improved in the United Kingdom in the last 50 years,[31] but this does not inevitably mean there will be a change in OHRQoL. However, our analysis has shown an overall improvement in OHRQoL in England between 1998 and 2009, both among the dentate adult population overall, but also within quasi-cohorts (through comparing different age groups between surveys to capture certain cohort effects during this eleven-year period).

An important challenge in evaluating changes relates to the different ways to score OHRQoL data, which may result in different interpretations. We initially used 4 different ways of scoring OHIP-14 data. For the sample overall, three of these showed statistically significant improvements in OHRQoL across the 11 years, and some of these differences were quite substantial; for example, there was an $11 \%$ reduction in OFOVO prevalence (Table 1). However, looking at the smaller group experiencing the more frequent problems (FOVO), there had been no reduction in prevalence at all, with the exception of the oldest group (aged 75+), probably related to their clear experience of retaining natural teeth unlike many of their predecessors. The issue, therefore, is that what we see as change over a period depends on where we "draw the line". The overall improvement in OHRQoL was predominantly among those that experienced oral impacts just occasionally, while the proportion of adults (around 15\%) with frequent oral impacts showed no difference between 1998 and 2009. We are not aware of any published data on changes in OHRQoL in other general adult populations for direct comparisons.

Focussing on three quasi-cohorts (capturing young, middle aged and older generations as they aged), we again showed non-significant changes in FOVOs, but significant improvements in the other three OHIP-14 outcomes in all three cohorts after 11 years (Table 2). This raises a question about whether resources should particularly concentrate on the group with frequent oral impacts, or whether focusing on those with less frequent impacts can yield further marginal improvements in OHRQoL. Previous studies investigating OHRQoL changes with age demonstrated either overall improvements or no change as cohorts aged but are limited to elderly cohorts.[10,11]

Having established the pattern of overall change in OHRQoL between equivalent age groups and ageing quasi-cohorts, we further decomposed these changes to allow a deeper understanding as to which factors can explain these changes. Looking at OFOVO prevalence change in the overall sample 
1 (Table 3), changes in demographic, socioeconomic and clinical oral health determinants collectively 2 accounted for $43 \%$ of the improvement in OHRQoL over this period. Most of this was down to changes in clinical oral health, specifically lower levels of decay/unsound teeth and fewer missing teeth, adding evidence that these clinical measures are a major determinant of OHRQoL.[32, 33] Increased age of the sample also accounted for some of the OHRQoL improvement, but sex, marital status, and socioeconomic position played no real role in this. When clinical variables were removed from the model, the change in OFOVO explained was greatly decreased (from $43 \%$ to $12 \%$ ), further highlighting the role of improved clinical oral health for the improvement in OHRQoL of the dentate general population over this period.

Decomposition analyses within the quasi-cohort groups revealed that different generations respond differently as they go through the aging process. For younger populations (aged 21-34 years in 1998 and 32-45 years in 2009), the age change itself over 11 years was not an important determinant of their considerable improvement in OHRQoL. This was in contrast to the older groups. For those aged 35-54 years in 1998 and $46-65$ years in 2009 , almost half of the explained improvement related to their increasing age, whilst in the oldest group (aged 55-74 years in 1998 and 66-85 years in 2009) this was more than $90 \%$. The importance simply of age in explaining OHRQoL improvements in the older generations may be a reflection of lower expectations regarding oral health and also perhaps of the relatively lower priority of oral health compared to increasing general health issues.[34] This research supports the concept that quality of life is a dynamic construct and people's perceptions,

In addition to ageing, improvements in occupational social class explained a substantial proportion of the improvement in OHRQoL for the youngest quasi-cohort only (12.9\%). The other significant contributors to OHRQoL changes within the quasi-cohorts were all measures of clinical oral health. However, effects varied between measure and quasi-cohort. Reductions in caries/unsound teeth contributed to the improvement in OHRQoL in all quasi-cohorts, but the contribution was considerably higher in the younger (21.6\%) than the older quasi-cohorts (just over $10 \%)$. In contrast, due to their cumulative nature, the number of missing teeth and presence of advanced periodontitis worsened over the eleven-year period and contributed to a decline in OHRQoL. The number of missing teeth contributed significantly across all three quasi-cohorts, but in a more substantive way among those in middle adulthood. Longitudinal studies of elderly cohorts also found that tooth loss contributed to declines in OHRQoL.[10, 11] The respective role of advanced periodontitis was 
1 modest for the two younger quasi-cohorts and non-significant for the oldest. Clearly, the contribution of these clinical factors to OHRQoL varies across the life course. Furthermore, they may well be tapping into different domains of OHIP-14, as missing teeth may primarily impact on function

$4 \quad$ while caries can potentially lead to pain.

6 Our decomposition models explained a considerable part of the improvement in OHRQoL over the 7 11-year period. However, there was still an overall $57 \%$ of the improvement among all adults, and 8 higher proportions for the two younger quasi-cohorts, which could not be explained. This may be partly due to unmeasured variables or changes in the strengths of associations between the assessed determinants and the outcome; for example, growing social inequalities in oral health between the two surveys. $[5,35,36]$ Such hypotheses were not addressed through our analyses. For the quasi-cohort analyses, the sample is not drawn from a true "cohort", but reflects changes in populations as they age over time. Therefore, we must be mindful that associations are being drawn at the population level, rather than at the individual level.

In summary, there were considerable improvements in the OHRQoL of dentate adults in England between 1998 and 2009, both for the population overall and across aging generations. These improvements were related to lower levels of occasional oral impacts in the population, but not to the frequent oral impacts experienced by fewer people. In the population overall, improvements in clinical oral health accounted for most of the explained improvement in OHRQoL. In the quasicohorts, the effect of aging itself and changes in clinical oral health accounted for most of the explained change, but the effect of these factors varied substantially across the lifecourse. These decomposition findings are relevant for health policy and public health action, as they can indicate which broader determinants could be primarily targeted to influence OHRQoL in different age groups or across different adult cohorts. 
2 What is already known on this subject?

3 - Oral diseases are highly prevalent with a considerable burden on people's quality of life.

4 - In high income countries, most oral diseases have declined in prevalence in the last 20 years.

5 - To date, no study has analysed time changes in oral health related quality of life and assessed to

6 what extent these have been influenced by sociodemographic and clinical factors in the context of

7 general improvement in clinical oral health.

9 What this study adds?

10 - This study assessed changes in oral health related quality of life between 1998 and 2009 among

11 adults in England and examined the contribution of demographic, socioeconomic and clinical oral

12 health characteristics.

13 - In this eleven year period, there was an overall improvement in oral health related quality of life, 14 though this was confined to the section of the population that reported infrequent oral impacts, 15 leaving a sizeable minority consistently reporting frequent oral impacts.

16 - The improvement in oral health related quality of life was explained mainly by changes in clinical 17 oral health and the effect of aging itself, but the contribution of the analysed determinants varied 18 substantially across the lifecourse and quasi-cohorts. 


\section{Competing Interest statement}

2 Competing Interest: None to declare

$4 \quad$ Funding

5 This research received no specific grant from any funding agency in the public, commercial or not-

6 for-profit sectors.

8 Licence for Publication

9 The Corresponding Author grants on behalf of all authors, an exclusive licence on a world wide basis

10 to the BMJ Publishing Group Ltd to permit this article (if accepted) to be published in JECH and any 11 other BMJPGL products.

\section{Contribution to authorship}

14 GT, JS and PFA conceived the study. GT, JS, PFA, ROC and CGH developed the analysis strategy; CGH 15 carried out the analyses; GT, JS, PFA, ROC, JW and CGH collectively interpreted the findings and 16 drafted the manuscript. All authors have read and approved the final manuscript.

\section{Ethics Approval Statement}

19 The ADHS 1998 was approved by the North Thames Multi-Centre Research Ethics Committee, and 20 the ADHS 2009 by the Oxford B Research Ethics Committee. For this specific analysis no protocol 21 approval was necessary because we obtained data from secondary sources. The data used was 22 already anonymized. 


\section{REFERENCES}

1 National Institute on Aging, National Institutes of Health, US Department of Health \& Human Services, et al. Global Health and Aging. Geneva, Switzerland. 2011.

2 Marcenes W, Kassebaum NJ, Bernabe E, et al. Global burden of oral conditions in 19902010: a systematic analysis. J Dent Res 2013;92:592-7.

3 Gerritsen AE, Allen PF, Witter DJ, et al. Tooth loss and oral health-related quality of life: a systematic review and meta-analysis. Health Qual Life Outcomes 2010;8:126.

4 Kassebaum NJ, Bernabe E, Dahiya M, et al. Global Burden of Severe Tooth Loss: A Systematic Review and Meta-analysis. J Dent Res 2014;93:20S-8S.

5 Roncalli AG, Sheiham A, Tsakos G, et al. Socially unequal improvements in dental caries levels in Brazilian adolescents between 2003 and 2010. Community dentistry and oral epidemiology 2015;43:317-24.

6 Watt $\mathrm{R}$, Sheiham A. Inequalities in oral health: a review of the evidence and recommendations for action. Br Dent J 1999;187:6-12.

7 Mackenbach JP, Kulhanova I, Menvielle G, et al. Trends in inequalities in premature mortality: a study of 3.2 million deaths in 13 European countries. J Epidemiol Community Health 2014.

8 Imkampe AK, Gulliford MC. Increasing socio-economic inequality in type 2 diabetes prevalence--repeated cross-sectional surveys in England 1994-2006. Eur J Public Health 2011;21:484-90.

9 Singh GK, Jemal A. Socioeconomic and Racial/Ethnic Disparities in Cancer Mortality, Incidence, and Survival in the United States, 1950-2014: Over Six Decades of Changing Patterns and Widening Inequalities. Journal of environmental and public health 2017;2017:2819372.

10 Enoki K, Ikebe K, Matsuda KI, et al. Determinants of change in oral health-related quality of life over 7 years among older Japanese. Journal of oral rehabilitation 2013;40:252-7.

11 Gulcan F, Nasir E, Ekback G, et al. Change in Oral Impacts on Daily Performances (OIDP) with increasing age: testing the evaluative properties of the OIDP frequency inventory using prospective data from Norway and Sweden. BMC oral health 2014;14:59.

12 Crocombe LA, Brennan DS, Slade GD. The influence of dental attendance on change in oral health-related quality of life. Community Dent Oral Epidemiol 2012;40:53-61.

13 Gagliardi DI, Slade GD, Sanders AE. Impact of dental care on oral health-related quality of life and treatment goals among elderly adults. Aust Dent J 2008;53:26-33.

14 Nuttall N, Tsakos G, Lader D, et al. Outcome and impact-A report from the Adult Dental Health Survey 2009. London: The NHS Information Centre for Health and Social Care 2011.

15 O'Sullivan I, Lader D, Beavan-Seymour C, et al. Foundation Report: Adult Dental Health Survey 2009 (Technical information). NHS Information Centre. 2011.

16 Kelly M, Steele J, Nuttall N, et al. Adult dental health survey: oral health in the United Kingdom 1998. London: Stationery Office 2000.

17 Slade GD. Assessment of oral health-related quality of life. In: Inglehart MR, Bagramian R, eds. Oral health-related quality of life: Quintessence Pub. 2002:29-46.

18 Allen PF. Assessment of oral health related quality of life. Health Qual Life Outcomes 2003;1:40.

19 Locker D, Quinonez C. To what extent do oral disorders compromise the quality of life? Community Dent Oral Epidemiol 2011;39:3-11.

20 Silvola AS, Rusanen J, Tolvanen M, et al. Occlusal characteristics and quality of life before and after treatment of severe malocclusion. European journal of orthodontics 2012;34:704-9.

21 Aleksejuniene J, Holst D, Eriksen HM, et al. Psychosocial stress, lifestyle and periodontal health. J Clin Periodontol 2002;29:326-35.

22 Slade GD, Nuttall N, Sanders AE, et al. Impacts of oral disorders in the United Kingdom and Australia. Br Dent J 2005;198:489-93. 
23 Yoon HS, Kim HY, Patton LL, et al. Happiness, subjective and objective oral health status, and oral health behaviors among Korean elders. Community Dent Oral Epidemiol 2013;41:45965.

24 Fairlie RW. An extension of the Blinder-Oaxaca decomposition technique to logit and probit models. J Econ Soc Meas 2005;30:305-16.

25 Sinning M, Hahn M, Bauer TK. The Blinder-Oaxaca decomposition for nonlinear regression models. The Stata Journal 2008;8:480-92.

26 Gonzalez Alvarez ML, Barranquero AC. Inequalities in health care utilization in Spain due to double insurance coverage: An Oaxaca-Ransom decomposition. Soc Sci Med 2009;69:793801.

1127 Wehby GL, Murray JC, McCarthy AM, et al. Racial gaps in child health insurance coverage in four South American countries: the role of wealth, human capital, and other household characteristics. Health Serv Res 2011;46:2119-38.

28 de Meijer C, Bakx P, van Doorslaer E, et al. Explaining declining rates of institutional LTC use in the Netherlands: a decomposition approach. Health Econ 2015;24 Suppl 1:18-31.

29 Bosomprah S, Aryeetey GC, Nonvignon J, et al. A decomposition analysis of change in skilled birth attendants, 2003 to 2008, Ghana Demographic and Health Surveys. BMC pregnancy and childbirth 2014;14:415.

30 Bennett DA. How can I deal with missing data in my study? Aust $N$ Z J Public Health 2001;25:464-9.

31 Steele JG, Treasure ET, O'Sullivan I, et al. Adult Dental Health Survey 2009: transformations in British oral health 1968-2009. Br Dent J 2012;213:523-7.

32 Lawrence HP, Thomson WM, Broadbent JM, et al. Oral health-related quality of life in a birth cohort of 32-year olds. Community Dentistry \& Oral Epidemiology;36:305-16.

33 Tan H, Peres KG, Peres MA. Retention of Teeth and Oral Health-Related Quality of Life.J Dent Res 2016;95:1350-7.

34 Slade GD, Sanders AE. The paradox of better subjective oral health in older age. J Dent Res 2011;90:1279-85.

35 Nasseh K, Vujicic M. The effect of growing income disparities on U.S. adults' dental care utilization. J Am Dent Assoc 2014;145:435-42.

36 Rozier RG, White BA, Slade GD. Trends in Oral Diseases in the U.S. Population. J Dent Educ 2017;81:eS97-eS109. 